\title{
МЕТАБОЛИЧЕСКИЙ СТАТУС ПРИ ПАТОЛОГИИ КОРОНАРНЫХ АРТЕРИЙ У ПАЦИЕНТОВ С НАРУШЕНИЕМ УГЛЕВОДНОГО ОБМЕНА
}

\author{
Омарова Н.Х., Солтаханов Э.М., Маммаев С.Н.
}

\begin{abstract}
ФГБОУ ВО «Дагестанский государственный медицинский университет» Минздрава России, Махачкала
\end{abstract}
ЦЕЛЬ: оценить углеводный, липидный, фосфорно-кальциевый обмен, уровень витамина $\mathrm{D}^{3}$ у пациентов с сахарным диабетом 2 типа (СД 2т) и у пациентов с состоянием преддиабета страдающих стенозом коронарных артерий, находившихся на стационарном лечении в «Научно-клиническое объединение «Дагестанский центр кардиологии и сердечно-сосудистой хирургии».

МАТЕРИАЛЫ И МЕТОДЫ: обследованная группа из 48 больных, с СД 2т и с состоянием преддиабета включала данные углеводного, липидного, фосфорно-кальциевого обмена, витамина $\mathrm{D}^{3}$ и данных ангиографии коронарных артерий. Проведено вычисление индекса массы тела (ИМТ) по общеизвестной формуле Кетле. Проведена оценка состояния углеводного обмена по результатам определения гликированного гемоглобина $\left(\mathrm{Hb}_{1 c}\right)$ глюкозы плазмы крови. Оценка поражения коронарных артерий проводилась по степени стеноза по данным коронарографии. Пациентам проводилось анкетирование, общеклиническое обследование, оценка показателей клинического и биохимического анализов крови, включая оценку уровня витамина $\mathrm{D}^{3}$.

РЕЗУЛЬТАТЫ: гендерное распределение составило 37(77,0\%) мужчин и 11 (22,9\%) женщин. Из 48 пациентов СД2т был у 26 (54,1\%), состояние преддиабета у 22 (45,8\%). При оценке ИМТ среднее значение

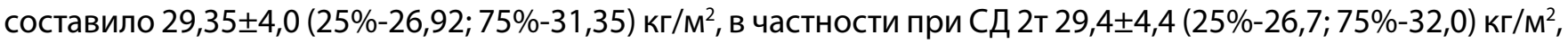

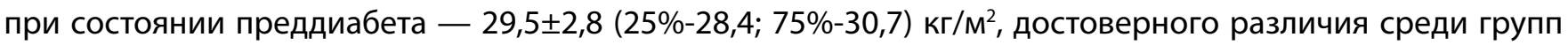

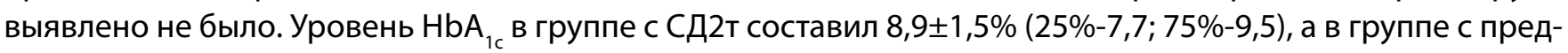
диабетом 6,1 $10,1 \%$ (25\%-6,0; 75\%-6,4). Уровень $\mathrm{HbA}_{1 с}$ у группы с СД2т достоверно отличался от группы

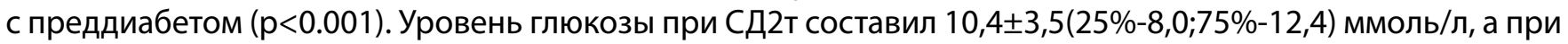
состоянии преддиабета 5,3 $\pm 0,7(25 \%-5,1 ; 75 \%-5,9)$ ммоль/л, с достоверным различием в группах ( $<<0.001)$. Анализ липидного профиля не выявил достоверного различия между уровнями ЛПНП у пациентов с СД2т $3,1 \pm 1,0$ (25\%-2,5; 75\%-3,7) ммоль/л, а в группе преддиабета - 3,1 11,4 (25\% - 2,4; 75\%-3,8) ммоль/л. Уровень триглицеридов у пациентов с СД2т составил - 2,8 2,0 (25\%-1,7;75\%-3,7) ммоль/л, а у пациентов с состоянием преддиабета 2,2士1,2(25\%-1,4;75\% -2,7) ммоль/л соответственно, достоверного различия выявлено не было. Уровень липопротеидов высокой плотности в обеих группах пациентов не отличался, среднее значение составило 1,0土0,2(25\%-0,9;75\%-1,1) ммоль/л. В обследуемых группах было также выявлено атеросклеротическое поражение коронарных артерий, по результатам проведенной коронарографии, различной степени стеноза. Уровень общего кальция у пациентов с СД2т и у пациентов с состоянием пред-

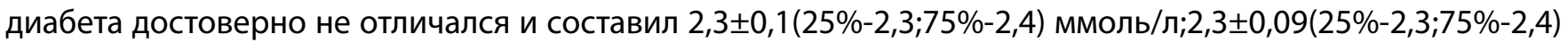
ммоль/л. Был выявлен дефицит витамина $\mathrm{D}^{3}$ в обеих группах, а также достоверное различие содержания

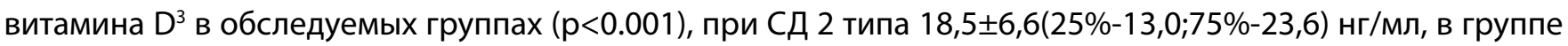

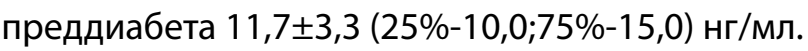

Выводы: выявлено нарушение липидного обмена и углеводного обмена у пациентов с сахарным диабетом 2 типа и с состоянием преддиабета. Выявлено атеросклеротическое поражение коронарных артерий обеих обследованных группах. Выявлен дефицит и достоверное различие в содержании витамина $\mathrm{D}^{3}$ в обеих обследованных группах.

КЛЮЧЕВЫЕ СЛОВА: сахарный диабет; витамин D; атеросклероз; инфаркт миокарда. 